\title{
Effects of exacerbations and seasonality on exhaled nitric oxide in COPD
}

\author{
A. Bhowmik, T.A.R. Seemungal, G.C. Donaldson and J.A. Wedzicha
}

\begin{abstract}
Exhaled nitric oxide (eNO) appears to be associated with airway inflammation seen in chronic obstructive pulmonary disease (COPD). The present authors studied the effects of exacerbation, season, temperature and pollution on eNO.

eNO was measured seasonally and at exacerbations in 79 outpatients suffering from COPD (mean forced expiratory volume in one second=42\%). The effects of exacerbation symptoms, physiological and environmental parameters were analysed.

Stable eNO levels were correlated positively with arterial oxygen tension. Median levels were found to be lower in smokers (5.3 ppb) than in ex- or nonsmokers (6.8 ppb). Levels were higher during October to December (6.9 ppb) than in April to June (4.6 ppb). Levels were also higher during 68 exacerbations in 38 patients $(7.4 \mathrm{ppb})$ than in stable conditions $(5.4 \mathrm{ppb})$, independent of the effects of smoking. The rise in eNO was greater in exacerbations that were associated with colds, a sore throat or dyspnoea combined with a cold.

In conclusion, exhaled nitric oxide levels were higher in colder weather and in the autumn, perhaps related to the increased prevalence of viral infection at this time of year. The levels were lower in more severe chronic obstructive pulmonary disease. Exhaled nitric oxide levels were raised at the onset of exacerbation, particularly in the presence of a cold.
\end{abstract}

KEYWORDS: Airway inflammation, cold, exacerbation, exhaled markers, temperature

hronic obstructive pulmonary disease (COPD) is characterised by progressive airflow obstruction [1] and frequent exacerbations associated with increased airway inflammation [2]. Exacerbations of COPD lead to a deterioration in the quality of life of these patients [3] and greater severity of COPD [4]. There is no universally accepted test to detect the onset of COPD exacerbations and the diagnosis of exacerbation relies on the subjective assessment of symptoms [3-5].

There is increasing evidence that exacerbations of COPD are inflammatory in their pathogenesis [6]. It has been shown that exacerbations associated with symptomatic colds are accompanied by greater levels of airway inflammation [2] and that rhinoviral infection causes greater rises in lower airway inflammation than nonrhinoviral inflammation [7]. Exhaled oral nitric oxide (eNO) has been shown to be both a marker of inflammation in asthma, and also to possess both pro-inflammatory and anti-inflammatory roles [8]. It has also been suggested that eNO is a marker of certain types of airway inflammation in COPD [9]. However, previous studies of eNO in COPD exacerbations have been limited by small sample sizes. Although it has been shown that patients hospitalised with COPD exacerbations had higher levels of eNO than when repeated several months later [10], there have been no prospective community studies of the changes in eNO during COPD exacerbations, nor are there any data on the relationship between the presence of symptoms of respiratory infection and eNO at such exacerbations. The current authors hypothesised that eNO might be associated with increased airway inflammation in exacerbations of COPD, particularly in the presence of colds. Therefore, a cohort of COPD patients was prospectively followed over a 12month period with daily monitoring of changes in symptoms and regular measurements of eNO in the outpatients department. The novel aspect of the present study is that changes in eNO were determined at COPD exacerbation and possible factors which affected this change were assessed. Air pollutant levels, season and daily outdoor temperature were included as cofactors in this analysis.

\section{PATIENTS AND METHODS \\ Study subjects}

The subjects included in this study were volunteers from the outpatient clinics at the London Chest Hospital (London, UK) and have been the
AFFILIATIONS

Academic Unit of Respiratory

Medicine, St. Bartholomew's and Royal London School of Medicine and Dentistry, London, UK.

\section{CORRESPONDENCE}

A. Bhowmik

Dept of Respiratory Medicine Homerton Hospital

Homerton Row

London

E9 6SR

UK

Fax: 442085107731

E-mail: A.Bhowmik@qmul.ac.uk

Received:

April 192005

Accepted after revision:

August 152005 
subject of previous analyses of data from the East London COPD study $[2,4,11]$. All patients had a diagnosis of COPD in accordance with previously published inclusion criteria $[2,12]$ and had been stable without oral corticosteroids for 4 weeks at the time of recruitment. Ethical permission for the study was obtained from the East London and City Health Authority Ethics Committee (both UK). Characteristics of all 98 patients who attempted to take part in the study are shown in table 1.

\section{Study design}

The current study was a prospective cohort study, examining eNO levels in patients during stable COPD and exacerbations. The effects of severity of COPD were assessed and measured by baseline lung function and blood gases. The effects of various symptoms of exacerbation, seasonality, temperature and air pollutants on eNO levels were assessed.

\section{Methods}

Measurements and follow-up

At recruitment, baseline measurements were recorded for: 1) height; 2) weight; 3) forced expiratory volume in one second (FEV1); 4) forced vital capacity (FVC) and post-medication peak expiratory flow (PEF) via a rolling seal spirometer (Sensor Medic Corp, Yorba Linda, CA, USA); 5) reversibility to $400 \mu \mathrm{g}$ inhaled salbutamol; and 6) arterialised ear lobe blood gases, which have been found accurate enough to be used in place of arterial blood gases, in clinical practice [13]. Smoking habits and details of inhaled and oral steroid use were also noted. The patients kept daily-diary cards on which they recorded their morning PEF, using a Mini-Wright peak flow meter (Clement Clarke International Ltd, Harlow, UK), and any increase over their chronic (stable) symptoms during the previous $24 \mathrm{~h}$. Patients were seen routinely in clinic every 3 months. They were also seen at the time of exacerbations.

\section{Exacerbations}

Respiratory symptoms were classified as "major" symptoms (dyspnoea, increased sputum purulence, increased sputum

\begin{tabular}{|c|c|}
\hline Characteristics & \\
\hline Male/female & $71 / 27$ \\
\hline Current smokers & $33(34)^{\#}$ \\
\hline Pack-yrs & $47.2 \pm 32.3$ \\
\hline On inhaled steroids & 89 \\
\hline Male & 63 \\
\hline Female & 26 \\
\hline Age yrs & $66.8(44-84)$ \\
\hline FEV 1 L & $1.11 \pm 0.44$ \\
\hline FEV $1 \%$ pred & $0.42 \pm 0.17$ \\
\hline FVC L & $2.56 \pm 0.83$ \\
\hline $\mathrm{Pa}, \mathrm{O}_{2} \mathrm{kPa}$ & $8.91 \pm 0.99$ \\
\hline $\mathrm{Pa}, \mathrm{CO}_{2} \mathrm{kPa}$ & $5.93 \pm 0.88$ \\
\hline
\end{tabular}

Data are presented as $n, n(\%)$, mean \pm SD or mean (range). FEV 1 : forced vital capacity in $1 \mathrm{~s}$; \% pred: percentage predicted; FVC: forced vital capacity; $\mathrm{Pa}, \mathrm{O}_{2}$; arterial oxygen tension; $\mathrm{Pa}, \mathrm{CO}_{2}$; carbon dioxide arterial tension. ${ }^{*}$ : two patients never smoked. quantity) or "minor" symptoms (wheeze, sore throat, cough and symptoms of a common cold, which were nasal congestion and/or nasal discharge). Exacerbations were defined as the presence for $\geqslant 2$ consecutive days of any two symptoms, at least one of which must have been a major symptom as previously described [3]. The first day counted was the date of onset of exacerbation. Patients were seen within $48 \mathrm{~h}$ and sampled prior to the initiation of any treatment, which was with a 10-day course of antibiotics and/or a course of oral steroids.

\section{Measurement of eNO}

The concentration of eNO was measured using a chemiluminescence analyser (Model LR 2000; Logan Research, Rochester, UK). Patients had to wait $\geqslant 1 \mathrm{~h}$ after smoking before an eNO measurement. Three readings were taken at intervals of $\sim 2$ min with the best curve selected for final analysis. An adequate exhalation manoeuvre was defined as one lasting $\geqslant 6 \mathrm{~s}$ and generating an eNO curve adequate to allow measurement of the eNO plateau [14]. The expiratory flow rate was kept at $\sim 5 \mathrm{~L} \cdot \mathrm{min}^{-1}$ against a resistance of $5 \mathrm{~cm} \mathrm{H} \mathrm{H}_{2} \mathrm{O}$, using a biofeedback light emitting diode. The sampling rate through the reaction chamber of the analyser was $250 \mathrm{~mL} \cdot \mathrm{min}^{-1}$, in keeping with previous work [15]. The analyser and the methods used met the recommendations of the American Thoracic Society/European Respiratory Society [14]. The eNO was measured during stable conditions, a minimum of 4 weeks away from an exacerbation. If a "stable" reading was not available prior to the onset of an exacerbation, a reading was obtained 4 weeks after recovery for comparison.

\section{Pollutants and temperature data}

Levels of ozone $\left(\mathrm{O}_{3}\right)$, nitrogen dioxide and particulate matter with a 50\% cut-off aerodynamic diameter of $10 \mu \mathrm{m}$ (PM10) were obtained from the Bloomsbury monitoring station in Central London via the AEA Technology website (AEA technology, NETCEN, Abingdon, UK). The outdoor temperature was taken as the average of maximum and minimum daily readings recorded at Heathrow Airport (London, UK; obtained from the Meteorological Office, UK).

\section{Analysis}

Data are presented as mean $\pm \mathrm{SD}$ or median (interquartile range; IQR) and statistical analysis was performed by parametric (unpaired t-test and ANOVA) or nonparametric (Wilcoxon matched-paired sign-rank test, Mann-Whitney two-sample test, Friedman test for several related samples and Spearman's rank correlation) tests where appropriate.

To determine the effects of season and pollutants on eNO in stable COPD, a regression model was fitted to the data using the cross-sectional time series regression command in STATA5 software.

\section{RESULTS}

\section{Factors affecting eNO at stable conditions}

In total, 98 patients were originally screened, but 19 were never able to perform an adequate baseline exhalation. In the 79 patients who could perform an adequate exhalation, the median (IQR) stable eNO was 5.9 (3.9-7.3). Those patients who were unable to perform the procedure were found to be older (mean \pm SD age: $71.0 \pm 6.5 \mathrm{yrs}$ ) than those who could 
perform the procedure $(65.8 \pm 8.1 \mathrm{yrs} ; \mathrm{p}=0.005)$. They were also found to have median FEV1 $(0.84 \mathrm{~L})$ and FVC $(1.73 \mathrm{~L})$ values that were lower than those who could perform the procedure (FEV1: 1.10; FVC: 2.66; fig. 1). Several readings were taken from each patient at stable conditions to assess variability. The within-subject coefficient of variation for eNO was $13.1,11.1$ and $11.5 \%$ for all subjects, smokers and nonsmokers, respectively.

Stable eNO was correlated positively with arterial oxygen tension $\left(\mathrm{Pa}_{2} \mathrm{O}_{2} ;\right.$ rho $\left.=0.234, \mathrm{p}=0.042\right)$ and negatively with carbon dioxide arterial tension $\left(\mathrm{Pa}_{1}, \mathrm{CO}_{2} ;\right.$ rho $=-0.333, \mathrm{p}=0.003$; fig. 2$)$. This relationship did not reach statistical significance in subgroup analysis looking at current and nonsmokers, except for the relationship between $\mathrm{Pa}, \mathrm{CO}_{2}$ and eNO in nonsmokers (rho=-0.314, $\mathrm{p}=0.026)$. Current smokers had lower median (IQR) eNO levels (5.30 (3.79-6.68) ppb) than nonsmokers (6.80 (5.27-9.08) ppb; $\mathrm{p}=0.001$, Mann-Whitney test). However, there was no relationship between $\mathrm{eNO}$ and the number of years of smoking or pack-years of smoking. Mean levels were taken for the whole year to correct for the effect of seasonal variation in these calculations. eNO levels were not associated with FEV1,


FIGURE 1. Box-whisker plots showing the median (interquartile range) differences in spirometry during stable conditions, between chronic obstructive pulmonary disease patients who were able $(a, n=79 ; b, n=79)$ to perform an adequate blow and those who were not $(a, n=19 ; b, n=19)$. a) Difference in forced expiratory volume in one second (FEV 1$): 1.10(0.80-1.40)$ versus $0.84(0.58-1.10)$; $p=0.003$. b) Difference in forced vital capacity (FVC): $2.66(2.05-3.42)$ versus 1.73 (1.43-2.32); $p<0.001$.

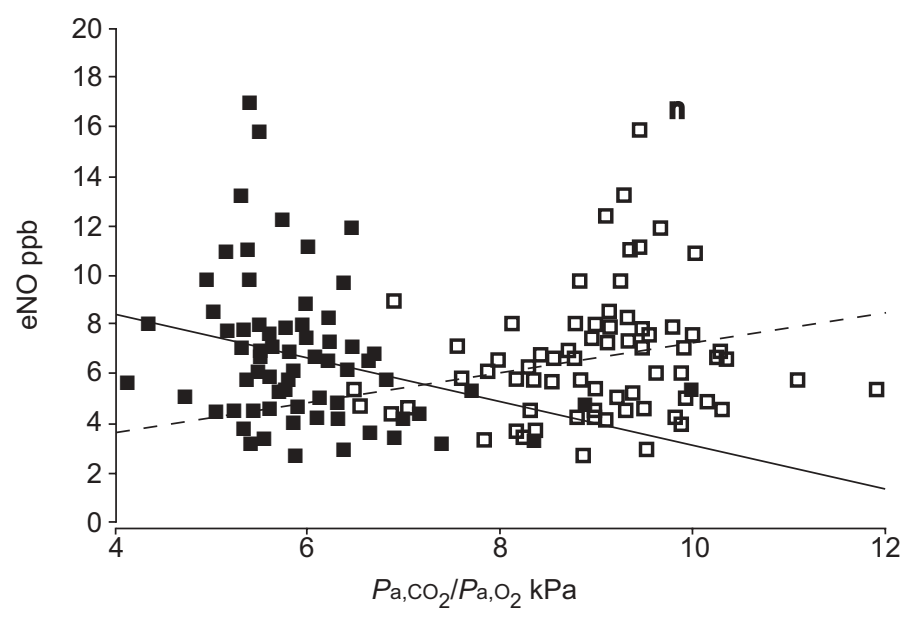

FIGURE 2. Graph to show the difference in exhaled nitric oxide (eNO) levels between ex-/nonsmokers and current smokers. $\mathbf{a}$ and $-: \mathrm{Pa}_{2} \mathrm{CO}_{2} ; \square$ and - - $\mathrm{Pa}, \mathrm{O}_{2} \cdot \mathrm{p}=0.004$.

FVC or exacerbation frequency in those patients who were able to perform an adequate exhalation. Those patients who were on inhaled steroids did not have significantly different eNO from those who were not on inhaled steroids, but there were only eight patients not taking inhaled steroids and, thus, it is difficult to draw any conclusions from this. There was no relationship between the dose of inhaled steroids and the eNO in current smokers or in ex-smokers ( $p>0.10$ in both cases). There were 13 patients using inhaled long acting $\beta$-agonists. There was no difference in eNO levels between these patients and those not using long acting $\beta$-agonists.

The levels of eNO in 14 subjects, who were sampled during stable conditions four times over the course of the year (fig. 3), were highest during the period from October to December (6.85 (4.90-7.60) ppb) and lowest in April to June (4.60 (3.456.48) $\mathrm{ppb} ; \mathrm{p}=0.005$, Friedman test). The mean percentage change was $52.7 \%$. The remainder of the patients did not have readings taken for all four seasons of the year and were excluded. The reasons for the absence of complete data

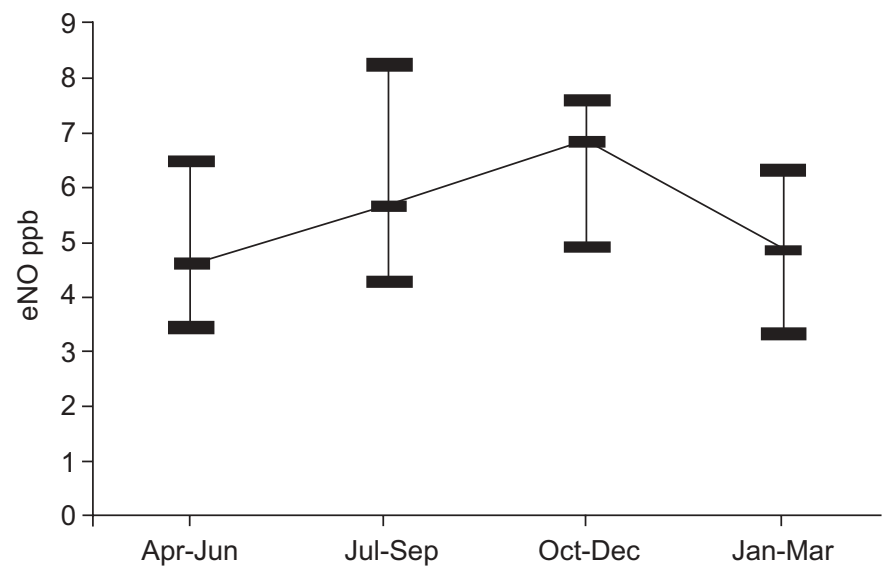

FIGURE 3. Median (interquartile range) levels of exhaled nitric oxide (eNO) in chronic obstructive pulmonary disease patients over $1 \mathrm{yr}$ showing highest levels during October to December $(n=14)$. $p=0.005$ 
included the inability to perform an adequate exhalation in all four seasons and failure to attend all the follow-up appointments. Patients who had an exacerbation during the 4 weeks prior to the exhalation reading were excluded to avoid the acute effects of exacerbation as opposed to the chronic effect of exacerbations during the last year. The subjects for whom data were obtained for all four seasons had a higher mean FVC $(3.03 \mathrm{~L})$ and $\mathrm{Pa}_{1} \mathrm{O}_{2}(9.49 \mathrm{kPa})$ than those for whom seasonal data was incomplete $(2.48 \mathrm{~L} ; \mathrm{p}=0.041 ; 8.82 \mathrm{kPa} ; \mathrm{p}=0.019$, respectively). Therefore, reflecting, in part, their slightly improved capacity to maintain an exhalation long enough to produce a satisfactory eNO curve all year round. The eNO levels were not related to prior exacerbation frequencies. eNO levels also rose with falling temperature independently of the season $(\mathrm{p}<0.001)$. Environmental $\mathrm{NO}, \mathrm{O}_{3}$ and PM10 were shown to have no effect on the levels of eNO in the present analysis.

\section{eNO at acute exacerbation}

Paired stable and exacerbation readings could be obtained in 67 exacerbations from 38 patients. The eNO level was significantly higher at exacerbation than when stable $(\mathrm{p}<0.001$; fig. 4). The eNO levels at exacerbation were correlated with the presence of a sore throat $(r h o=0.271$, $\mathrm{p}=0.023)$, but not with other symptoms. The changes in eNO at exacerbation were not related to the current smoking status or the previous smoking history. No relationship was found between the exacerbation frequency in the previous year and the mean eNO at stable conditions.

eNO changed by $1.90(-0.40-4.00)$ ppb at COPD exacerbation (percentage change $38.6(-5.6-85))$. Table 2 shows that the change was significantly higher in those exacerbations which were associated with the symptoms of a cold, sore throat or the combination of dyspnoea and a cold. Figure 5 shows the magnitudes of these changes in the presence or absence of a cold or a sore throat.

\section{DISCUSSION}

This is the first study to prospectively investigate the production of eNO from the lower airway in a large number of patients with moderate-to-severe COPD both in stable

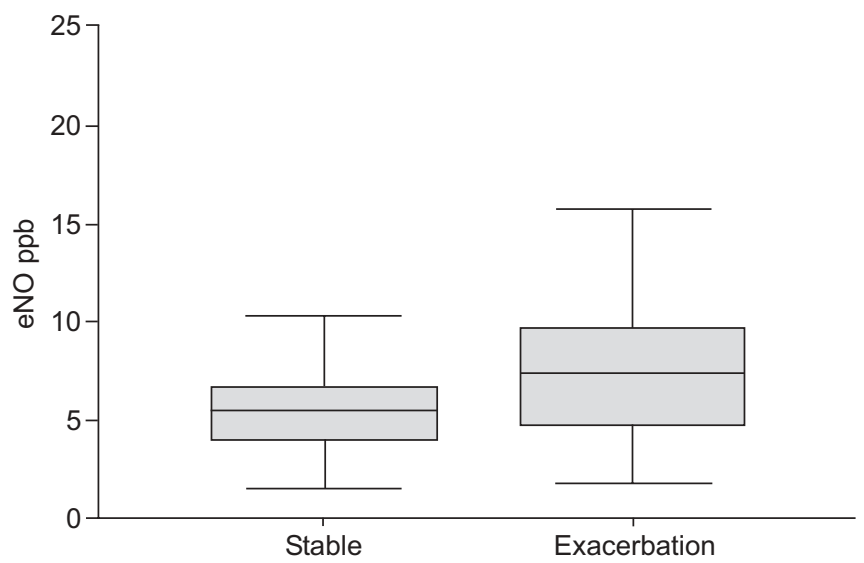

FIGURE 4. Box-whisker plots showing exhaled nitric oxide (eNO) levels at stable chronic obstructive pulmonary disease $(5.40$ (4.00-6.70)) and exacerbation (7.40 (4.80-9.60)). $p<0.001$.

\begin{tabular}{|c|c|c|c|c|c|}
\hline \multirow{3}{*}{$\begin{array}{l}\text { TABLE } 2 \\
\text { Symptom }\end{array}$} & \multicolumn{5}{|c|}{$\begin{array}{l}\text { lationship between exacerbation symptoms } \\
\text { d magnitude of change in exhaled nitric oxide } \\
\text { JO) from stable condition to exacerbation }\end{array}$} \\
\hline & \multicolumn{2}{|l|}{ Present } & \multicolumn{2}{|l|}{ Absent } & \multirow[t]{2}{*}{ p-value } \\
\hline & Median (IQR) & $\mathbf{n}$ & Median (IQR) & $\mathbf{n}$ & \\
\hline $\begin{array}{l}\text { Increased } \\
\text { dyspnoea }\end{array}$ & $1.90(-0.20-4.40)$ & 53 & $1.70(-0.75-3.10)$ & 14 & NS \\
\hline $\begin{array}{l}\text { Increased sputum } \\
\text { purulence }\end{array}$ & $1.55(-1.13-4.08)$ & 22 & $1.90(0.00-4.00)$ & 45 & NS \\
\hline $\begin{array}{l}\text { Increased sputum } \\
\text { quantity }\end{array}$ & $1.40(-1.00-3.35)$ & 41 & $2.35(0.38-5.43)$ & 26 & NS \\
\hline Cold & $2.80(0.65-5.75)$ & 29 & $0.85(-0.88-2.73)$ & 38 & 0.012 \\
\hline Sore throat & $4.90(1.40-8.05)$ & 13 & $1.25(-0.45-2.83)$ & 54 & 0.022 \\
\hline $\begin{array}{l}\text { Increased } \\
\text { dyspnoea and } \\
\text { cold }\end{array}$ & $2.80(0.85-6.75)$ & 21 & $0.90(-0.65-2.80)$ & 46 & 0.016 \\
\hline
\end{tabular}

conditions and at exacerbations. The present results show that smokers have lower levels of eNO than compared with exsmokers in stable COPD, and that stable eNO was highest in
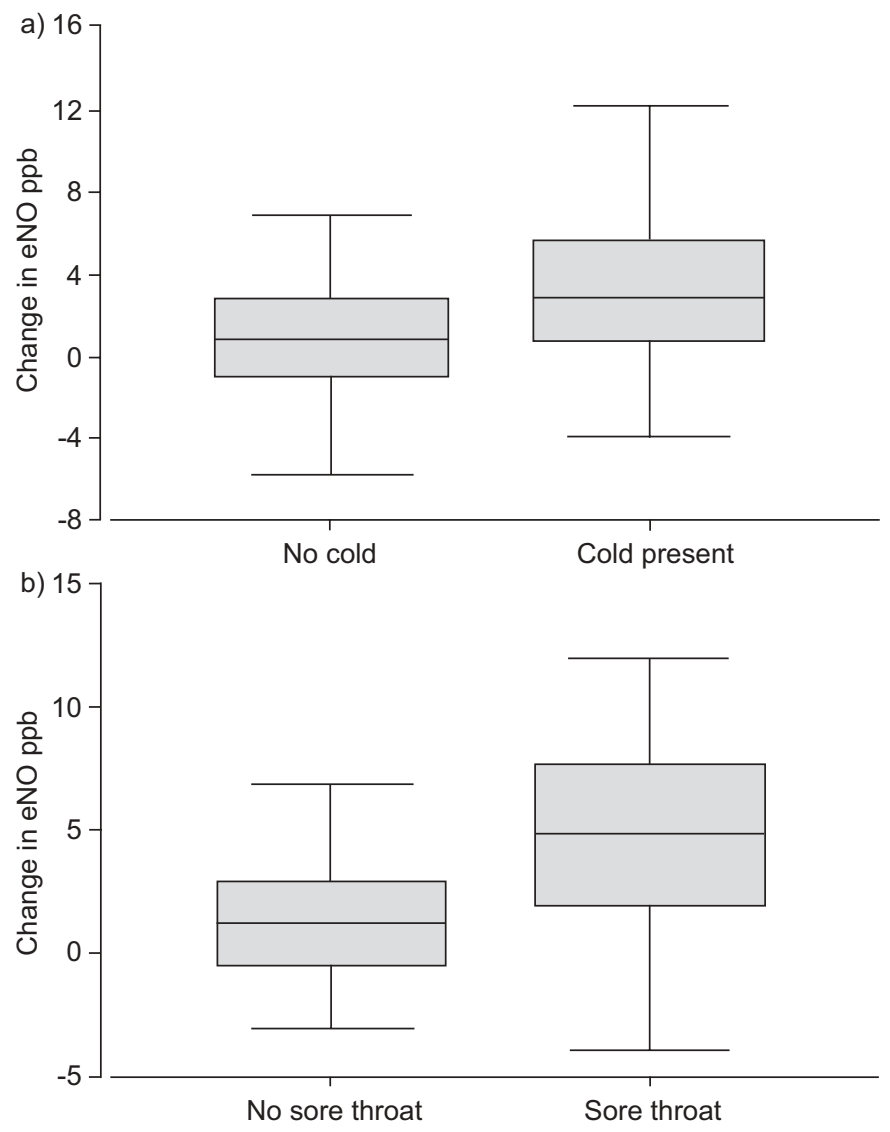

FIGURE 5. a) Change in exhaled nitric oxide (eNO) at exacerbation in the presence $(n=29)$ or absence of a cold $(n=38) \cdot p=0.012$. b) Change in eNO at exacerbation in the presence $(n=13)$ or absence of sore throat $(n=54)$. $p=0.022$. 
the months of October, November and December. eNO increased during COPD exacerbation and the magnitude of this increase was greater during symptomatic colds.

Stable eNO in smokers was found to be lower than in nonsmokers. This has previously been documented in asthmatics and in healthy controls [16]. It is considered to be a result of several factors, including down regulation of $\mathrm{NO}$ synthase by the high concentration of NO in cigarette smoke and direct damage to the cells producing NO by the smoke [17]. However, no relationship was found between eNO and pack-years of smoking.

There was also no relationship found between FEV1, FVC and eNO. There may not have been enough variation to find a significant effect as only $15 \%$ of the patients had a FEV1 \% predicted of $>60 \%$. Data has been conflicting on the relationship between FEV1 and eNO. Some studies have shown a positive correlation [18], whereas others have shown a negative correlation [19]. However, these studies are difficult to interpret because of differences in such factors as unstable disease and smoking status. The present authors found that levels of eNO were positively correlated with $\mathrm{Pa}_{\mathrm{a}} \mathrm{O}_{2}$ and negatively correlated with $\mathrm{Pa}_{\mathrm{a}} \mathrm{CO}_{2}$, implying diminished $\mathrm{NO}$ production in the more hypoxic and more severe COPD patients. This is in keeping with the findings of CLINI et al. [18], although this was not seen in another study using a different eNO analyser in a less severe group of nonsmoking COPD patients [20]. The present results are consistent with the theory that in patients with more severe COPD there is destruction of the airway epithelial cells. These are considered to be the site of NO production [21], therefore, this results in lower eNO levels. The relationship between blood gases and eNO was only lost in current smokers $(n=28)$, perhaps due to the smaller levels of eNO in these patients. In ex-smokers, the relationship between eNO and $\mathrm{Pa}, \mathrm{CO}_{2}$ remained present, although that between eNO and $\mathrm{Pa}, \mathrm{O}_{2}$ no longer reached statistical significance, probably because of the smaller number of patients $(n=51)$.

Of the 79 patients, 71 were on inhaled steroids. No correlation was found between the dose of inhaled corticosteroids taken by the patients and eNO. Inhaled steroids have been shown to reduce levels of eNO in COPD as reported in a study by FERREIRA et al. [22]. This may be because the severity of COPD in that particular study was not as great as that observed in patients in the current study. The median levels of eNO in the study by FERREIRA et al. [22], using a different analyser, were also significantly higher at $26.2 \mathrm{ppb}$, falling after 1 week of beclometasone by $10.6 \mathrm{ppb}$. Therefore, the lower eNO levels seen in the present study, which are believed to be due to greater disease severity, may mask any changes that might be observed with variations in inhaled steroid dosage.

eNO rose significantly at exacerbation from 5.40 to $7.40 \mathrm{ppb}$ in the current study, independently of smoking. This was a rise of $38.6 \%$. This change was greater in the presence of colds, sore throat and colds with shortness of breath at exacerbation. It has previously been shown that these symptoms are associated with virus detection during COPD exacerbation [23]. This provides further evidence to suggest that lower airway viral infection causes increased airway inflammatory response, as seen in exacerbations of COPD. The current authors have previously shown that rhinovirus RNA can be directly identified by sampling sputum from the lower airway [7]. Induction of inducible NO synthase is regulated by transcription factors, most importantly nuclear factor- $\kappa \beta$ (NF- $\kappa \beta)$ [24]. Viral infections may induce epithelial cell NF- $\kappa \beta$ [25], thus, increasing eNO. Previous studies have also shown that an upper respiratory tract infection causes increases in eNO [26]. The method of exhalation against a resistance of $5 \mathrm{~cm} \mathrm{H}_{2} \mathrm{O}$ has previously been shown adequate to prevent contamination of the sample by nasal NO [14]. Since it is lower airway NO that is measured, this observation supports the hypothesis that direct infection of the lower airway may be the mechanism through which eNO rises at exacerbation.

This is the first study to look at changes in eNO levels in COPD patients during seasonal changes over a complete year. The data showed that the highest eNO was found during October to December. Previous work from the authors' centre has shown that a fall in temperature is associated with deterioration in lung function [27], which may be caused by increased viral or bacterial infection of the lower airways during this season. It has been found that respiratory viruses can be detected in the nasal aspirates of $16-23 \%$ of stable COPD patients [7, 23]. This infection may not actually cause a symptomatic exacerbation, but may lead to increased inflammation of the lower airway and activation of NF- $\kappa \beta$, resulting in an increased production of NO [24]. Hence, in this study, no relationship was found between previous exacerbation frequency and eNO levels in the stable state. However, there were only 14 patients included in the seasonal analysis and a larger number may be required to detect the effect of previous exacerbation frequency in this context. The incidence of rhinovirus infection has been shown to peak in autumn with smaller outbreaks in spring [28], thus, accounting for the authors' findings of a raised eNO from October to December. However, raised eNO levels later in winter may be found, depending on local viral infection patterns.

Pollutants may also have a role in the increased airway inflammation seen during the winter although previous studies have not demonstrated any conclusive evidence. No effect of air pollutants on the levels of stable eNO was found in this study. Although it is recommended that contamination with environmental NO be avoided when measuring eNO online as a relationship [29], it has also been observed, by various workers, that ambient $\mathrm{NO}$ levels have no effect on eNO plateau $[30,31]$ so it is not surprising that no such effect was found. It seems that the effect of ambient $\mathrm{NO}$ is of less importance when using online sampling, measuring the plateau of the curve unlike the situation in offline sampling.

In total, 19 of the 98 patients were never able to perform an adequate eNO recording. The inability of a large number of patients to perform an adequate exhalation illustrates the limitations of this technique in assessing the condition of the airways of those patients who suffer from very severe COPD. Those who were never able to perform this test were older and had significantly poorer lung function than those who were able to exhale at the required force and for the necessary duration. They were unable to sustain a breath long enough to reach the plateau phase of the eNO curve and did not have enough control over their exhalation to maintain the correct 
oral pressure. Smoking history and medication did not differ between the two groups. This suggests that it may have been age related deterioration in lung function that led to difficulties in performing the exhalation manoeuvre. Therefore, it is apparent that the equipment currently used for online measurement of eNO is not appropriate for a proportion of patients with the most severe COPD. This technical difficulty excluded a number of patients with the most severe disease from this study. However, it is worth mentioning that although expiratory flow rate of $5 \mathrm{~L} \cdot \mathrm{min}^{-1}$ was used, with a side arm sampling flow rate of $250 \mathrm{~mL} \cdot \mathrm{s}^{-1}$ for online $\mathrm{NO}$ analysis, as previously used by some workers [15], more recent studies suggest an expiratory flow rate of $0.05 \mathrm{~L} \cdot \mathrm{s}^{-1}\left(3 \mathrm{~L} \cdot \mathrm{min}^{-1}\right)$ and it is possible that this lower rate might have allowed some of the patients to achieve an adequate exhalation [14].

In conclusion, the present study shows an increase in exhaled nitric oxide at exacerbation of chronic obstructive pulmonary disease, independent of the smoking status, confirming the role of inflammation in such episodes. The rise in exhaled nitric oxide at exacerbation is greater in the presence of symptomatic colds. Moreover, it is possible that sub-clinical viral infections in late autumn to winter may be responsible for an increase in airway inflammatory activity without symptomatic exacerbations. However, the small size of the increase in exhaled nitric oxide at exacerbation, as well the large seasonal variation in exhaled nitric oxide, diminishes its usefulness as a marker of exacerbation. Further study is required to clarify the role of exhaled nitric oxide in detecting respiratory viral infections.

\section{ACKNOWLEDGEMENTS}

The authors would like to thank M. Roland for assistance with data collection and the FH Muirhead Charitable Trust for providing funding for the nitric oxide analyser used in this study.

\section{REFERENCES}

1 Fletcher C, Peto R. The natural history of chronic airflow obstruction. BMJ 1977; 1: 1645-1648.

2 Bhowmik A, Seemungal TA, Sapsford RJ, Wedzicha JA. Relation of sputum inflammatory markers to symptoms and lung function changes in COPD exacerbations. Thorax 2000; 55: 114-120.

3 Seemungal TA, Donaldson GC, Paul EA, Bestall JC, Jeffries DJ, Wedzicha JA. Effect of exacerbation on quality of life in patients with chronic obstructive pulmonary disease. Am J Respir Crit Care Med 1998; 157: 1418-1422.

4 Donaldson GC, Seemungal TAR, Bhowmik A, Wedzicha JA. Relationship between exacerbation frequency and lung function decline in chronic obstructive pulmonary disease. Thorax 2002; 57: 847-852.

5 Rodriguez-Roisin R. Toward a consensus definition for COPD exacerbations. Chest 2000; 117: Suppl. 2, 398S-401S.

6 Crooks SW, Bayley DL, Hill SL, Stockley RA. Bronchial inflammation in acute bacterial exacerbations of chronic bronchitis: the role of leukotriene B4. Eur Respir J 2000; 15: 274-280.

7 Seemungal TA, Harper-Owen R, Bhowmik A, Jeffries DJ, Wedzicha JA. Detection of rhinovirus in induced sputum at exacerbation of chronic obstructive pulmonary disease. Eur Respir J 2000; 16: 677-683.

8 Kharitonov SA, Yates D, Robbins RA, Logan-Sinclair R, Shinebourne EA, Barnes PJ. Increased nitric oxide in exhaled air of asthmatic patients. Lancet 1994; 343: 133-135.

9 Papi A, Romagnoli M, Baraldo S, et al. Partial reversibility of airflow limitation and increased exhaled $\mathrm{NO}$ and sputum eosinophilia in chronic obstructive pulmonary disease. Am J Respir Crit Care Med 2000; 162: 1773-1777.

10 Agusti AG, Villaverde JM, Togores B, Bosch M. Serial measurements of exhaled nitric oxide during exacerbations of chronic obstructive pulmonary disease. Eur Respir J 1999; 14: 523-528.

11 Seemungal TA, Donaldson GC, Bhowmik A, Jeffries DJ, Wedzicha JA. Time course and recovery of exacerbations in patients with chronic obstructive pulmonary disease. Am J Respir Crit Care Med 2000; 161: 1608-1613.

12 Pauwels RA, Buist AS, Calverley PM, Jenkins CR, Hurd SS. Global Strategy for the diagnosis, management, and prevention of chronic obstructive pulmonary Disease. NHLBI/WHO Global Initiative for Chronic Obstructive Lung Disease (GOLD) Workshop Summary. Am J Respir Crit Care Med 2001; 163: 1256-1276.

13 Pitkin AD, Roberts CM, Wedzicha JA. Arterialised earlobe blood gas analysis: an under used technique. Thorax 1994; 49: 364-366.

14 ATS/ERS Recommendations for standardized procedures for the online and offline measurement of exhaled lower respiratory nitric oxide and nasal nitric oxide, 2005. Am J Respir Crit Care Med 2005; 171: 912-930.

15 Kharitonov SA, Barnes PJ. Nasal contribution to exhaled nitric oxide during exhalation against resistance or during breath holding. Thorax 1997; 52: 540-544.

16 Persson MG, Zetterstrom O, Agrenius V, Ihre E, Gustafsson LE. Single-breath nitric oxide measurements in asthmatic patients and smokers. Lancet 1994; 343: 146-147.

17 Kharitonov SA, Robbins RA, Yates D, Keatings V, Barnes PJ. Acute and chronic effects of cigarette smoking on exhaled nitric oxide. Am J Respir Crit Care Med 1995; 152: 609-612.

18 Clini E, Bianchi L, Pagani M, Ambrosino N. Endogenous nitric oxide in patients with stable COPD: correlates with severity of disease. Thorax 1998; 53: 881-883.

19 Maziak W, Loukides S, Culpitt S, Sullivan P, Kharitonov SA, Barnes PJ. Exhaled nitric oxide in chronic obstructive pulmonary disease. Am J Respir Crit Care Med 1998; 157: 998-1002.

20 Ansarin K, Chatkin JM, Ferreira IM, Gutierrez CA, Zamel N, Chapman KR. Exhaled nitric oxide in chronic obstructive pulmonary disease: relationship to pulmonary function. Eur Respir J 2001; 17: 934-938.

21 Kharitonov SA, Chung KF, Evans D, O'Connor BJ, Barnes PJ. Increased exhaled nitric oxide in asthma is mainly derived from the lower respiratory tract. Am J Respir Crit Care Med 1996; 153: 1773-1780.

22 Ferreira IM, Hazari MS, Gutierrez C, Zamel N, Chapman KR. Exhaled nitric oxide and hydrogen peroxide in patients with chronic obstructive pulmonary disease: 
effects of inhaled beclomethasone. Am I Respir Crit Care Med 2001; 164: 1012-1015.

23 Seemungal T, Harper-Owen R, Bhowmik A, et al. Respiratory viruses, symptoms, and inflammatory markers in acute exacerbations and stable chronic obstructive pulmonary disease. Am J Respir Crit Care Med 2001; 164: 1618-1623.

24 Xie Q, Kashiwabara Y, Nathan C. Role of transcription factor NF-kappa B/Rel in induction of nitric oxide synthase. J Biol Chem 1994; 269: 4705-4708.

25 Papi A, Johnston SL. Rhinovirus infection induces expression of its own receptor intercellular adhesion molecule 1 (ICAM-1) via increased NF-kappa B-mediated transcription. J Biol Chem 1999; 274: 9707-9720.

26 Murphy AW, Platts-Mills TA, Lobo M, Hayden F. Respiratory nitric oxide levels in experimental human influenza. Chest 1998; 114: 452-456.
27 Donaldson GC, Seemungal TAR, Jeffries DJ, Wedzicha JA. Effect of temperature on lung function and symptoms in chronic destructive pulmonary disease. Eur Respir J 1999; 13: 844-849.

28 Heikkinen T, Jarvinen A. The common cold. Lancet 2003; 361: 51-59.

29 Adamkiewicz G, Ebelt S, Syring M, et al. Association between air pollution exposure and exhaled nitric oxide in an elderly population. Thorax 2004; 59: 204-209.

30 Silkoff P, McClean P, Slutsky A, et al. Marked flowdependence of exhaled nitric oxide using a new technique to exclude nasal nitric oxide. Am J Respir Crit Care Med 1997; 155: 260-267.

31 Piacentini GL, Bodini A, Vino L, et al. Influence of environmental concentrations of $\mathrm{NO}$ on the exhaled $\mathrm{NO}$ test. Am J Respir Crit Care Med 1998; 158: 1299-1301. 